\title{
Coordination and Output Attainment in Work Units Performing Non-routine Tasks: A Cross- National Study
}

\author{
Joseph L. C. Cheng, Edwin L. Miller*
}

Joseph L. C. Cheng Department of Management, Virginia Polytechnic Institute and State University. Blacksburg. Virginia 24061. U.S.A.

Edwin L. Miller Graduate School of Business, University of Michigan. Ann Arbor, Michigan 48109

U.S.A.
Organization Studies

$1985,6 / 1: 23-39$

(C) $1985 \mathrm{EGOS}$

$0170-8406 / 85$

$0006-0002 \$ 1.00$

\section{Abstract}

Based on an information-processing perspective (Galbraith 1972), a theoretical proposition is advanced which predicts that for work units performing non-routine tasks, the effect of unit coordination on output attainment is contingent on the sources from which the unit acquires information for task performance. This proposition is tested using a cross-national research design. Data from four national samples - Austria, Belgium, Hungary, and Poland - of academic research units support the proposition. The results reinforce the need for a contingency approach to the study of coordination and performance in organizations. They also provide some insight into the interplay between society and organization.

\section{Introduction}

A basic objective in social science research is to identify those regularities which are universal and those which are situation-specific. In organization studies, coordination is generally regarded as a universal organizational problem, the resolution of which is essential to the effective functioning of any organization (Georgopoulos 1970; Lawrence and Lorsch 1967; Mintzberg 1979). Implicit in the above thinking is the assumption of a universal relationship between coordination and organizational performance;i.e. the better coordinated the organization the higher the organizational performance.

The validity of this assumption was called into question in a recent study of interdependence and coordination in organizations (Cheng 1983). Data from a national sample of research units in Belgium indicate that coordination contributed to research unit productivity only to the extent that there was a high level of interdependence between unit members. In units where there was a low level of interdependence, coordination did not contribute to research unit productivity. Motivated by these findings, a follow-up study was conducted to investigate the relationship between coordination and research unit productivity across different scientific fields (Cheng 1984). Results show that in the developed fields (physical sciences and engineering), coordination was positively related to productivity. No such relationship, however, was found in the undeveloped fields (social sciences).

Taken together, these two sets of findings indicate that the relationship between coordination and organizational performance is not as universal as is commonly depicted in the literature. Given that most major theoretical models include coordination as a basic explanatory variable of organizational perform- 
ance (e.g. Georgopoulos 1970; Lawrence and Lorsch 1967; Mintzberg 1979), additional research is needed to identify other contingency variables which may affect the strength and/or direction (positive/negative) of the coordination-performance relationship. The study reported below represents one such effort.

\section{The Present Study}

The purpose of this study is to investigate further the contingency effect of coordination on organizational performance at the work unit level of analysis. Based on an information-processing perspective (Galbraith 1972), a theoretical proposition is advanced which predicts that for work units performing nonroutine tasks, the effect of unit coordination on output attainment is contingent on the sources from which the unit acquires information for task performance. This proposition is tested using a cross-national research design. Data from four national samples - Austria, Belgium. Hungary, and Poland - of academic research units support the proposition. The results, along with those from the two earlier analyses (Cheng 1983; 1984), suggest a three dimensional contingency framework for the study of coordination and performance in organizations. They also have some important implications for future crossnational research on organizations.

The present study extends past research in several major ways. First, previous studies based on the information-processing perspective focus primarily on the amount of information processed as a predictor of organizational performance (e.g. Katz and Tushman 1979; Tushman 1978). This investigation extends the work of the researchers just mentioned by examining sources of information as a contingency variable in relation to coordination and performance in organizations. Second, with a few notable exceptions (e.g. Pugh 1981; Tannenbaum, Kavcic, Rosner, Vianello, and Wieser 1974), most of the crossnational studies that have been done on organizations are of a 'one-shot' nature (see review by Bhagat and McQuaid 1982). Consequently, many of the findings of these investigations tend to be non-cumulative and difficult to interpret. The research reported here is built upon knowledge generated from two previous studies based on data from Belgium (Cheng 1983; 1984). As such, it represents a systematic progression from single-nation to multiple-nation investigations which, according to Roberts (1970) and others, is a more effective approach to cross-national research on organizations. Finally, the existing cross-national literature on organizations is primarily micro-oriented (see reviews by Hickson. Hinings, McMillan and Schwitter 1974; Bhagat and McQuaid 1982), focusing on societal influences on individual attitudes and behaviours in organizations. This study adds to the literature by investigating organization-society interactions at the work unit level of analysis. 


\section{Background and Theoretical Analysis}

At the most basic level, coordination concerns the unity of effort, or concerted action, among organizational members (Georgopoulos and Mann 1962; Lawrence and Lorsch 1967; Thompson 1967). In more operational terms, coordination represents the extent to which the work activities of organizational members are logically consistent and coherent (Cheng 1983; 1984). A well coordinated organization is characterized by a high degree of coherence in its functioning. That is, the various work activities are performed in such ways that they supplement and complement one another, and are directed towards a common objective. On the other hand, a poorly coordinated organization is characterized by fragmented activities, and a lack of unified functioning.

According to Galbraith (1972), an organization can be viewed as a system of patterned activities involving the transmission, interpretation, and synthesis of task-related information. As such. coordination can be conceptualized as representing the extent to which these activities supplement and complement one another. A high level of coordination would mean that the activities are performed in such ways that they reinforce one another in information processing. That is, information processed by activity A can be logically related to and combined with information processed by activities B, C, and D, etc. Conversely, a low level of coordination would mean that the various information-processing activities are unrelated to, or incompatible with, one another.

Based upon the above conceptualization, a contingency relationship between coordination and organizational output attainment can be established as follows. From the perspective of organizations as input-throughput-output systems (Katz and Kahn 1978), output attainment represents a joint outcome of (1) the relevancy of the information acquired by the organization (the input component), and (2) the extent to which the acquired information is synthesized or coordinated (the throughput component). As such, coordination will contribute to output attainment only to the extent that the input information is relevant to task performance. The more relevant the input information, the greater the contribution of coordination to output attainment.

There are two major ways through which work units in organizations acquire information for task performance (March and Simon 1958; Thompson 1967). The first is to rely on policies or procedures as the primary source of information. The second is to rely on feedback from the task itself. According to Galbraith (1977), policies or procedures are solutions made in advance based on past experience. As such, the information they provide is relevant to task performance only to the extent that the task is routine or repetitive. If the task is non-routine, past experience may not be relevant to task performance. Here, work participants need to adapt their actions based on information learned from the task as it unfolds. These ideas suggest that to ensure relevant input information. work units performing non-routine tasks should rely less on 
policies/procedures and more on task feedback as the primary source of information for task performance.

The above theoretical analysis can be summarized into the following proposition: For work units performing non-routine tasks, the effect of unit coordination on output attainment varies with the relevancy of the input information which, in turn, is contingent on the sources from which the unit acquires information for task performance. If the unit relies more on task feedback and less on policies/procedures as the primary source of information, the input information will be relevant to task performance. Consequently, coordination will have a positive effect on output attainment. If the unit relies more on policies/procedures and less on task feedback as the primary source of information, the input information may not be relevant to task performance. Consequently, coordination may have a negative effect on output attainment.

\section{A Cross-National Design}

In an attempt to test the above proposition, a cross-national research design was employed. According to Bhagat and McQuaid (1982), cross-national settings are naturally occurring social experiments which might provide a strategic site for the testing of hypotheses on organizations. Consistent with this view, four European nations - Austria, Belgium. Hungary, and Poland were selected to form the comparative base for this investigation. These countries were chosen because previous research indicates that they differ in their characteristic approaches to organizational management. Specifically, Soviet Bloc countries, such as Hungary and Poland, place much greater emphasis on central planning and control in organizational management than do the non-Soviet Bloc countries (Brzezinski 1967; Chandler 1978; Kuc, Hickson, and McMillan 1980). This approach to organizational management has the effect of restricting the acquisition of task information of work units to one primary source - policies and procedures provided by higher level authorities. On the other hand, non-Soviet Bloc countries, such as Austria and Belgium, place much greater emphasis on decentralization and member initiative in organizational management than do the Soviet Bloc countries (Haire, Ghiselli, and Porter 1966; Harbison and Myers 1959; Tannenbaum and Cooke 1979). This approach has the effect of facilitating the acquisition of task information of work units from sources other than policies and procedures, such as feedback from the task. Hence, a comparison of organizational management in these four nations permits one to test the proposition under two naturally-occurring 'experimental' conditions: (1) high reliance on policies/procedures and low reliance on task feedback (as represented by work units in the Hungarian and Polish organizations), and (2) low reliance on policies/procedures and high reliance on task feedback (as represented by work units in the Austrian and Belgian organizations). (Empirical support for this classification is presented under the heading Results.)

The work units on which this study is based are research units located in 
university settings. These work units were chosen for three reasons. First, consistent with the cross-national differences described above, research activities within the Hungarian and Polish universities are more closely guided by formal policies and procedures (from central planning authorities) than those within the Austrian and Belgian universities (see Albright 1970; Klima and Viehoff 1977; Krauze, Kowalewski, and Podgorecki 1977; Szalai 1968). Specifically, universities in Hungary and Poland are directly controlled by the state, and research activities are governed by a unified science policy developed by the national Academy of Sciences. By contrast, universities in Austria and Belgium are autonomous in matters of internal operation. Academic freedom is provided by law in both countries, and faculty members have direct control over their research activities.

Second, according to Perrow (1967), scientific research falls under his classification of non-routine tasks. This type of work is characterized by a high degree of variation in both (a) the kinds of problems encountered in the conversion process, and (b) the methods used in solving those problems.

Third, academic research units provide a strategic site for assessing societal or country effect on organizational functioning. while holding the variables of work technology and institutional environment constant. This is because (a) the technology employed in research work is fairly universal within scientific disciplines, particularly in the developed fields (Kuhn 1962: Lodhal and Gordon 1972), and (b) the institutional values of universities (e.g. commitment to the advancement of knowledge and its dissemination through publication channels) are quite uniform across different societies (Clark 1980; Parsons 1951). Negandhi (1974) and Roberts (1970) have pointed out that the influence of work technology and institutional environment must be controlled before one can assess societal/country effect on organizations.

\section{Statement of Hypothesis}

Earlier, a theoretical proposition was advanced which predicts that for work units performing non-routine tasks, the effect of unit coordination on output attainment is contingent on the sources from which the unit acquires information for task performance. Based on the cross-national design described above. this proposition can now be tested by comparing the relationship between coordination and research unit output across the four nations included here. Specifically, it is hypothesized that in the Austrian and Belgian universities. where research units rely more on task feedback and less on policies/procedures as the primary source of task information, coordination will be positively related to research unit output. In the Hungarian and Polish universities, where research units rely more on policies/procedures and less on task feedback as the primary source of task information, coordination will be negatively related to research unit output. 


\section{Methodology}

\section{Sample}

Data for this investigation came from a UNESCO sponsored project, the International Comparative Study on the Organization and Performance of Research Units (see Andrews 1979a). A research unit was formally defined as a group of scientists which meets the requirements of having specific scientifictechnical responsibilities, a distinct life-span, one recognized leader, and at least three core members each of whom spends a minimum of eight hours per week in the unit.

The sample used for this investigation was a purposefully selected subset of the original sample of the UNESCO project. Specifically, the present sample consisted of 80 research units sampled from 36 different universities: 8 universities were in Austria, 10 universities in Belgium, 11 universities in Hungary, and 7 universities in Poland. The units were selected in each country by means of a multi-stage, stratified, probability sampling procedure. Of these units, about two-thirds were within the academic structures (departments/ colleges) of the universities. The rest were located in research institutes closely associated with and managed by the universities. The research units were about evenly distributed among the four comparison subsamples. Twenty-seven percent $(\mathrm{N}=22)$ of the units were in Austria. 24 percent $(\mathrm{N}=19)$ in Belgium, 20 percent $(N=16)$ in Hungary, and 29 percent $(N=23)$ in Poland. The four subsamples were 'matched' on two task-related variables. First, all the units were reported by their heads as being those performing the kind of research that required unit members to work closely with one another (as opposed to individually). Thus, levels of interdependence within the units were held uniform across comparison subsamples. Second, all the units were performing research in developed scientific fields: physics and chemistry, engineering, and medical sciences. Previous analyses (Cheng and McKinley 1983) indicate that research units in the developed fields operate quite differently from those in the undeveloped fields.

\section{Data Collection}

The data were collected using a combination of personal interviews (with unit heads), on-site administration of standardized questionnaires (to staff scientists in the unit), and organizational records (for information on unit output). All data collection instruments were translated, through a back-translation process, into the native languages of the participating countries. Furthermore, they had been pretested and revised twice before being used for the final round of data collection. A detailed description of the construction of instruments and sampling procedures is provided by Andrews (1979a). 


\section{Measures}

\section{Independent Varlable}

Coordination was assessed with a modified version of Georgopoulos and Mann's (1962) coordination measure. This measure has shown high reliability and validity (Price 1972). Staff scientists were asked to indicate (on a five-point scale) the extent to which (1) the research programme of the unit was coherent (as opposed to fragmented), and (2) the research planning in the unit was wellconceived. The homogeneity of unit members responses was tested for the appropriateness of pooling using analysis of variance. As pooling was found appropriate $(p<.05)$, individual responses were combined to form unit scores. The alpha coefficient of the coordination index was .78.

\section{Dependent Variable}

Research unit output was assessed in terms of three types of scientific output that the unit had produced during the previous three years: (1) the number of books published, (2) the number of journal articles published outside the country, and (3) the number of journal articles published within the country. Because the original output scores showed skewed distributions, they were all transformed to lognormal scores using the Pelz and Andrews (1966: 271-274) procedure. To adjust for the uneven scientific importance of the three types of output, a weight of 3 was assigned to the number of books published, 2 to the number of journal articles published outside the country, and 1 to the number of articles published within the country. These weightings were based on judgments of the relative importance of various types of written research output by an international panel of scientists and research administrators associated with the UNESCO project (see Andrews, 1979a: 36-38). A composite index was constructed by summing the weighted, transformed scores across items.

\section{Control Varlables}

Four variables were included as controls. This was done to control for their main effects on unit output, and possible confounding effects on the hypothesized relationships. The first was unit size, measured in terms of the number of staff scientists in the unit. The second was the research emphasis of the unit's parent organization. This was measured by asking the unit head to respond (on a five-point scale) to the following question: 'How strongly research-minded is the governing board of the organization to which your unit belongs?' The third was the basic/applied orientation of the research unit. This was represented by a dummy variable. coded 1 for the physics. chemistry. and medical science units, and 0 for the engineering units. The fourth was unit motivation, measured with a three-item index (on a five-point scale) developed by Andrews (1979b): (1) the extent to which there is an atmosphere of great dedication to work in the unit, (2) the amount of voluntary overtime put in by the staff scientists, and (3) the extent to which the staff scientists consider their 
work to be interesting. Data for this measure were collected from the staff scientists. Using analysis of variance, the homogeneity of unit members' responses was tested for the appropriateness of pooling. As pooling was found appropriate $(p<.05)$, individual responses were combined to form unit scores. The alpha coefficient of the unit motivation index was .71 .

In addition to the above variables, two other measures - the extent to which unit activities were guided by (a) task feedback and (b) formal policies - were included to validate the present classification of the comparison sub-samples into the two 'experimental' conditions described above: (1) high reliance on task feedback and low reliance on policies/procedures, and (2) low reliance on task feedback and high reliance on policies/procedures. If the classification is valid, one would expect that in Austria and Belgium, unit activities would be more guided by task feedback than by formal policies. In Hungary and Poland, unit activities would be more guided by formal policies than by task feedback.

Data for these two measures were collected by asking the unit head to indicate, in percentage terms, the extent to which the unit's choice of research themes was determined by (1) the scientific nature of the research task, and (2) guidelines and/or instructions provided by three higher levels of authority: national science policy-making bodies, authority controlling the organization to which the unit belongs, and the governing organ(s) of the parent organization. This was asked in interviews, in conjunction with two other questions measuring the extent of influence from other sources. The six percentages summed to 100 .

Tables 1 and 2 present, respectively, the descriptive statistics and zero-order correlations among the study variables.

\section{Results}

\section{Validation of the Classification Scheme}

The mean values for the task feedback and formal policies variables (see rows 1 and 2 in Table 1) confirm the present classification of the comparison nations. In Austria and Belgium, the choice of unit research themes was more guided by task feedback ( $45 \%$ and $67.89 \%$, respectively) than by formal policies ( $15.91 \%$ and $11.58 \%$, respectively). The opposite pattern was found in Hungary and Poland. There, the choice of unit research themes was more guided by formal policies ( $40.94 \%$ and $34.35 \%$, respectively) than by task feedback ( $33.75 \%$ and $28.04 \%$, respectively). ANOVA-tests show that between-sample differences were significant for both variables: $F=9.16(p<.0001)$ for task feedback, and $F=8.37$ ( $\mathrm{p} .<.0001$ ) for formal policies. These results are consistent with the comparison nations' characteristic approaches to organizational management described in the section headed Cross-National Design. They also support the use of these four national settings as research sites for the testing of the hypothesis. 
Table 1

Descriptive Statistics for Study Variables by Nation

Table 2

Zero-Order

Correlations Among

Study Variables $(N=80$

Work Units)

\begin{tabular}{|c|c|c|c|c|c|}
\hline \multirow[b]{2}{*}{ Variable } & & \multicolumn{4}{|c|}{ Nation } \\
\hline & & $\begin{array}{l}\text { Austria } \\
(\mathrm{N}=22)\end{array}$ & $\begin{array}{l}\text { Belgium } \\
(N=19)\end{array}$ & $\begin{array}{l}\text { Hungary } \\
(N=16)\end{array}$ & $\begin{array}{l}\text { Poland } \\
(\mathrm{N}=23)\end{array}$ \\
\hline Task Feedback & & $\begin{array}{c}45.00 \\
(32.18)\end{array}$ & $\begin{array}{c}67.89 \\
(28.54)\end{array}$ & $\begin{array}{c}33.75 \\
(25.85)\end{array}$ & $\begin{array}{c}28.04 \\
(19.52)\end{array}$ \\
\hline Formal Policies & & $\begin{array}{c}15.91 \\
(28.52)\end{array}$ & $\begin{array}{c}11.58 \\
(23.34)\end{array}$ & $\begin{array}{c}40.94 \\
(31.26)\end{array}$ & $\begin{array}{c}34.35 \\
(20.02)\end{array}$ \\
\hline Unit Size & $\cdot$ & $\begin{array}{c}6.82 \\
(3.46)\end{array}$ & $\begin{array}{c}8.37 \\
(4.11)\end{array}$ & $\begin{array}{c}6.13 \\
(2.09)\end{array}$ & $\begin{array}{c}7.83 \\
(4.33)\end{array}$ \\
\hline Unit Motivation & $:$ & $\begin{array}{l}4.02 \\
(.46)\end{array}$ & $\begin{array}{l}3.84 \\
(.89)\end{array}$ & $\begin{array}{l}4.02 \\
(.60)\end{array}$ & $\begin{array}{l}4.09 \\
(.44)\end{array}$ \\
\hline Research Emphasis & . & $\begin{array}{c}4.09 \\
(1.44)\end{array}$ & $\begin{array}{l}4.37 \\
(.90)\end{array}$ & $\begin{array}{c}3.00 \\
(1.26)\end{array}$ & $\begin{array}{c}3.52 \\
(1.24)\end{array}$ \\
\hline Basic/Applied ${ }^{\mathbf{b}}$ & & $\begin{array}{l}.57 \\
(.50)\end{array}$ & $\begin{array}{l}.60 \\
(.50)\end{array}$ & $\begin{array}{l}.94 \\
(.24)\end{array}$ & $\begin{array}{l}.58 \\
(.50)\end{array}$ \\
\hline Coordination & & $\begin{array}{l}3.26 \\
(.84)\end{array}$ & $\begin{array}{l}3.37 \\
(.86)\end{array}$ & $\begin{array}{l}3.65 \\
(.61)\end{array}$ & $\begin{array}{l}3.68 \\
(.76)\end{array}$ \\
\hline Unit Output $^{\mathrm{c}}$ & & $\begin{array}{c}8.54 \\
(5.08)\end{array}$ & $\begin{array}{l}13.20 \\
(4.05)\end{array}$ & $\begin{array}{l}11.79 \\
(4.13)\end{array}$ & $\begin{array}{l}8.25 \\
(4.82)\end{array}$ \\
\hline
\end{tabular}

${ }^{a}$ First entries in the columns are the mean values of the variables. Second entries (in parentheses) are the standard deviations.

b Dummy variable ( 1 =physics, chemistry, and medical science units; $0=$ engineering units).

c Lognormal scores.

\begin{tabular}{lcccccccc}
\hline Variable & V1 & V2 & V3 & V4 & V5 & V6 & $V^{*}$ & V. \\
\hline V1. Task Feedback & - & $-.61^{* *}$ & $.28^{*}$ & .15 & 17 & $31^{*}$ & 13 & $.33^{* *}$ \\
V2. Formal Policies & & - & -.00 & -.20 & .10 & -.08 & .09 & -.10 \\
V3. Unit Size & & & - & .08 & .03 & $.27^{*}$ & .05 & $.38^{* *}$ \\
V4. Unit Motivation & & & - & .03 & $.25^{*}$ & $.61^{* *}$ & .01 \\
V5. Research Emphasis & & & & - & -.05 & .04 & -.01 \\
V6. Basic/Applied & & & & & & - & $.26^{*}$ & $.30^{* *}$ \\
V7. Coordination & & & & & & & - & -.01 \\
V8. Unit Output & & & & & & & & - \\
\hline
\end{tabular}

$* * \mathrm{p}<.01$ (two-tailed)

$* \mathrm{p}<.05$ (two-tailed)

\section{Testing of Hypothesis}

Two analytic procedures were used to test the hypothesis: (1) analysis of covariance and (2) subgroup analysis. Analysis of covariance was used to test for an interaction effect of coordination and country on unit output. Subgroup 
Table 3

Analysis of Covariance for Unit Output analysis was used to obtain information about the magnitude and direction of the coordination-unit output relationship for each national subsample. The hypothesis would be supported if (1) the analysis of covariance results were to show a significant interaction effect of coordination and country on unit output. and (2) the subgroup analysis results were to show that the relationship between coordination and unit output is positive in the Austrian and Belgian subsamples, and negative in the Hungarian and Polish subsamples.

Table 3 presents the results of analysis of covariance. As indicated by the increase in variance explained at the final step (where the cross-product term was entered), coordination and country had a significant interaction effect on unit output $\left(\Delta \mathrm{R}^{2}=7.2 \% ; \mathrm{p}=.0488\right)$, after controlling for the main affects of unit size, unit motivation, research emphasis of the parent organization, basic/ applied orientation of the unit, coordination, and country. These results indicate that the relationship between coordination and unit output differed significantly across the four national subsamples.

\begin{tabular}{llrrrr}
\hline Source & $\mathrm{df}$ & Sum of Sq & \multicolumn{1}{c}{$\mathrm{R}^{2}$} & $\mathrm{~F}$ & $\mathrm{P}$ \\
\hline Unit Size & 1 & 305.59 & $14.6 \%$ & 16.76 & .0001 \\
Unit Motivation & 1 & .60 & $0 \%$ & 0.03 & .8570 \\
Research Emphasis & 1 & .52 & $0 \%$ & 0.03 & .8668 \\
Basic/Applied & 1 & 98.51 & $4.7 \%$ & 5.40 & .0230 \\
Coordination & 1 & 4.80 & $0.2 \%$ & .26 & .6096 \\
Country & 3 & 281.26 & $13.4 \%$ & 5.14 & .0030 \\
Cooordination X Country & 3 & 150.15 & $7.2 \%$ & 2.75 & .0488
\end{tabular}

Total $\mathbf{R}^{2}=40.1 \%$

Total Sum of Squares $=2099.28$

The above findings are confirmed by the subgroup analysis results (see Table 4). As hypothesized, the regression coefficients for coordination were all positive in the Austrian $(b=2.18)$ and Belgian $(b=5.84)$ subsamples, but were all negative in the Hungarian $(b=-.23)$ and Polish $(b=-3.57)$ subsamples. Taken together, these two sets of results provide strong support for the hypothesis.

\section{Additional Analyses}

To further examine the contingency effect of unit coordination on output attainment, additional analyses were performed using the task feedback and formal policies measures as a contingency variable alternative to country. If the hypothesis is valid, one would expect the following results: the more the choice of unit research themes is guided by task feedback and the less by formal policies (i.e. the greater the task feedback/formal policies ratio), the more positive the relationship between coordination and unit output. 
Table 4

Subgroup Analysis Results by Nation

\begin{tabular}{|c|c|c|c|c|c|}
\hline \multirow[b]{2}{*}{ Predictor } & & \multicolumn{4}{|c|}{ Nation } \\
\hline & & Austria & Belgium & Hungary & Poland \\
\hline Unit Size & & $\begin{array}{c}.69 \\
(.34)\end{array}$ & $\begin{array}{l}.26 \\
(.19)\end{array}$ & $\begin{array}{l}.78 \\
(.60)\end{array}$ & $\begin{array}{c}.34 \\
(.25)\end{array}$ \\
\hline Unit Motivation & 8 & $\begin{array}{c}-1.32 \\
(3.30)\end{array}$ & $\begin{array}{c}-5.71^{+} \\
(1.56)\end{array}$ & $\begin{array}{c}1.81 \\
(2.41)\end{array}$ & $\begin{array}{c}2.66 \\
(2.37)\end{array}$ \\
\hline Research Emphasis & & $\begin{array}{l}-.26 \\
(.83)\end{array}$ & $\begin{array}{l}1.70 \\
(.83)\end{array}$ & $\begin{array}{c}.70 \\
(1.10)\end{array}$ & $\begin{array}{c}-.38 \\
(.73)\end{array}$ \\
\hline Basic/Applied & $\therefore \quad: \because:$ & $\begin{array}{c}4.59^{+} \\
(2.15)\end{array}$ & $\begin{array}{l}-.66 \\
(1.73)\end{array}$ & $\begin{array}{l}-.10 \\
(5.14)\end{array}$ & $\begin{array}{c}1.99 \\
(2.23)\end{array}$ \\
\hline Coordination & & $\begin{array}{c}2.18 \\
(1.63)\end{array}$ & $\begin{array}{l}5.84^{* *} \\
(1.73)\end{array}$ & $\begin{array}{l}-.23 \\
(2.43)\end{array}$ & $\begin{array}{r}-3.57^{*} \\
(1.31)\end{array}$ \\
\hline $\mathrm{R}^{2}=$ & $\therefore \quad \therefore \quad \therefore$ & $52 \%$ & $62 \%$ & $22 \%$ & $40 \%$ \\
\hline
\end{tabular}

Note: Coefficients are the unstandardized regression coefficients. Numbers in parentheses are the standard errors.

$+p<.05$ (two-tailed for control variables)

* $p=.005$ (one-tailed for hypothesized relationships)

- $p=.014$ (one-tailed for hypothesized relationships)

To test the above relationship, the sample was divided into three approximately equal groups which ranked low, medium, and high on the task feedback/formal policies ratio. As shown in Table 5, the regression coefficients for the coordination-unit output relationship changed from $b=-2.62$ in the low group, to $b=1.22$ in the medium group, to $b=2.41$ in the high group. Results from t-tests show that the differences in the regression coefficients

\begin{tabular}{|c|c|c|c|c|c|}
\hline \multirow{2}{*}{\multicolumn{2}{|c|}{ Predictor }} & & \multicolumn{3}{|c|}{ Task Feedhack Formal Policies Ratio } \\
\hline & & & Low & Medium & $\mathrm{H}$ igh \\
\hline Unit Size & & & $\begin{array}{l}.13 \\
(.28)\end{array}$ & $\begin{array}{c}.68 \\
(.35)\end{array}$ & $\begin{array}{r}.81^{+} \\
(.22)\end{array}$ \\
\hline Unit Motivation & & & $\begin{array}{c}2.33 \\
(2.12)\end{array}$ & $\begin{array}{c}.02 \\
(2.22)\end{array}$ & $\begin{array}{c}-4.53^{+} \\
(1.64)\end{array}$ \\
\hline Research Emphasis & & & $\begin{array}{l}.61 \\
(.79)\end{array}$ & $\begin{array}{c}-1.57 \\
(1.15)\end{array}$ & $\begin{array}{c}.41 \\
(.55)\end{array}$ \\
\hline Basic/Applied & & 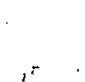 & $\begin{array}{c}3.31 \\
(2.14)\end{array}$ & $\begin{array}{l}-1.76 \\
(3.55)\end{array}$ & $\begin{array}{c}3.46 \\
(1.89)\end{array}$ \\
\hline Coordination & & & $\begin{array}{l}-2.62 \\
(1.68)\end{array}$ & $\begin{array}{c}1.22 \\
(3.09)\end{array}$ & $\begin{array}{l}2.41^{*} \\
(1.04)\end{array}$ \\
\hline $\mathbf{R}^{2}=$ & & & $165^{\circ}$ & $: \because ;$ & $\therefore \because$ \\
\hline
\end{tabular}

Note: Coefficients are the unstandardized regression coefficients. Numbers in parentheses are the standard errors

$+<.05$ (two-tailed for control variables)

* $=.015$ (one-tailed for hypothesized relationships)
Table 5

Subgroup Analysis

Results by Task

Feedback/Formal

Policies Ratio 
across groups were all significant by a one-tailed test: medium vs. low groups $(\Delta \mathrm{b}=3.84 ; \mathrm{t}=4.80, \mathrm{p}<.01)$, high vs. low groups $(\Delta \mathrm{b}=5.03 ; \mathrm{t}=15.24$, $\mathrm{p}<.01)$, high vs. medium groups $(\Delta \mathrm{b}=1.19 ; \mathrm{t}=1.60 ; \mathrm{p}<.06)$. Taken together, these findings provide additional support for the hypothesized contingency effect of coordination on unit output. They also confirm the earlier analyses using country as a contingency variable.

\section{Discussion}

The purpose of this study has been to further investigate the contingency effect of coordination on organizational performance at the work unit level of analysis. Using a cross-national design, results support the proposition that for work units performing non-routine tasks, the effect of coordination on unit output is contingent on the sources from which the unit acquires information for task performance. In the Austrian and Belgian universities, where research units rely more on task feedback and less on policies/procedures as the primary source of information, coordination is positively related to unit output. In the Hungarian and Polish universities, where research units rely more on policies/ procedures and less on task feedback as the primary source of information, coordination was negatively related to unit output. The proposition is further supported by a parallel test using the task feedback and formal policies measures as a contingency variable alternative to country. Results show that the more the choice of unit research themes was guided by task feedback and the less by formal policies, the more positive the relationship between coordination and unit output. Taken together, these findings substantiate the need for a contingency approach to the study of coordination and performance in organizations (Cheng $1983 ; 1984$ ). They also demonstrate the potential of using cross-national settings as research sites for the testing of hypotheses on organizations (Bhagat and McQuaid 1982).

Thus far, the discussion has assumed that the primary direction of causality in these findings is from coordination to unit output. Because the present study is based on cross-sectional data, it is possible that the causal direction might be the reverse. One might hypothesize, for example, that unit output has a causal effect on the unit's quality of coordination. If this were indeed the case, one would expect such effects to be more or less uniform across all units. The present findings, however, show that the relationship between coordination and unit output differed significantly across the four comparison subsamples. If one is to infer from the present findings a causal relationship from unit output to coordination, it would be necessary to explain, on theoretical grounds, why increased unit output leads to better coordination in the Austrian and Belgian universities, and poorer coordination in the Hungarian and Polish universities. No such theoretical explanation is forthcoming from the organization theory literature, however. Based on the above reasoning, it seems appropriate to infer that the original specification of causality is more probable, and that the primary direction of effect is from coordination to unit output. 
In addition to the above findings, the present study also provides some interesting information about university and research unit functioning in the four comparison nations (see descriptive statistics reported in Table 1). On average, universities in Austria and Belgium tend to be less bureaucratic and place greater emphasis on research than their counterparts in Hungary and Poland. However, research units in the Hungarian and Polish universities seem to be better coordinated but publish less than those in the Austrian and Belgian universities. These findings are potentially significant in that they may serve as input to the design of future studies on universities in the Soviet Bloc and nonSoviet Bloc countries. They also reinforce the utility of considering the sociopolitical characteristics of nations (e.g. the governance structure) as a potential source of variation in organizational functioning (Heydebrand 1973; Tannenbaum, Kavcic, Rosner, Vianello, and Wieser 1974).

\section{Implications}

Several theoretical and research implications can be derived from the present findings. First, this study, along with the two earlier analyses (Cheng 1983; 1984). strongly reject the premise of a universal relationship between coordination and organizational performance. at least for the specific case of work units performing scientific research. Instead, they indicate that the effect of unit coordination on research output is contingent on (1) the level of interdependence between unit members, (2) the scientific field (or environmental context) in which the unit operates, and (3) the sources from which the unit acquires information for task performance. Taken together, these findings suggest a three-dimensional contingency framework for the study of coordination and performance in organizations. Future researchers may wish to investigate the validity of this framework using different samples, and to extend its application to the study of coordination and performance at the organizational level of analysis.

Second. from a comparative standpoint. this study reinforces the utility of considering 'societal prescriptions/preferences' (Meyer, 1978) as a conceptual base for assessing the effect of society on organizations. In his analysis, Meyer points to the prescriptions or preferences of societies as a determinant of management practices and argues that such prescriptions may create institutionalized non-rationalities 'in organizations. Although the focus of this study is not on societal effect per se, it does provide some insight into the interplay between society and organization. Specifically, the present findings suggest that one way societies may affect organizations is through their prescriptions or preferences for certain approaches to organizational management. In countries where a 'mechanistic' approach to organizational management is prescribed or preferred, organizational units performing non-routine tasks will not benefit from coordination. On the other hand, in countries where an 'organic' approach to organizational management is prescribed or preferred, the same organizational units will benefit from coordination. Additional research is needed to further explore the usefulness of the societal prescrip- 
tions/preferences ' construct, thus leading to a better understanding of the role of society in organizational inquiry.

Finally, within the past several years, there has been a great deal of criticism regarding the lack of theoretical and methodological rigour in cross-national organization research. Roberts (1970) and Bhagat and McQuaid (1982), for example, have observed that most cross-national organization studies (1) are not guided by theory. (2) select comparison nations based on location or convenience of data, rather than their standings on some theoretical variable relevant to the research problem. (3) do not employ standardized measures, and (4) do not control for possible confounding effects of theoretically relevant variables. Along similar lines, Schollhammer (1973) and Miller and Cheng (1978), have noted that statistical analysis in many empirical studies is weak, and rarely are more advanced statistical methods - such as multivariate techniques - used. This study has made an effort to avoid these shortcomings in both the research design and data analysis. The results support the claims of comparative theorists (e.g. Crozier 1964; Etzioni 1971; Heydebrand 1973) that cross-national differences represent an important source of variation in organizational functioning. If cross-national research is to contribute to the advancement of knowledge about organizations, researchers must take the above criticisms seriously and take steps to overcome them. The study reported here represents a step in that direction.

- The authors wish to thank O.S. and its anonymous reviewers for their helpful comments. This paper has also benefited from the comments of Bill McKinley, Vlado Pucik, and Al Schick

\section{References}

Albright, Arnold D.

1970 Management des universites en Belgique. Brussels: Institut Administration Universite.

Andrews, Frank M., (ed.)

1979a Scientific productivity: The effectiveness of research groups in six countries. Cambridge: Cambridge University Press.

Andrews, Frank $M$

$1979 \mathrm{~b}$ 'Motivation, diversity, and the performance of research units' in Scien. tific productivity: The effectiveness of research groups in six countries. F. M. Andrews (ed.), 253-289. Cambridge: Cambridge University Press.

Bhagat, Rabi S., and Sara J. McQuaid

1982 'Role of subjective culture in organizations: A review and directions for future research'. Journal of Applied Psychology 67: 653-685.
Brzezinski, Zbigniew $\mathrm{K}$

1967 The Solviet Bloc: Unity and conflict, revised edition. Cambridge: Harvard University Press.

Chandler, Margaret K.

1978 'Project management in the Socialist Bloc'. Columbia Journal of World Business, Summer, 71-86.

Cheng, Joseph L. C

1983 'Interdependence and coordination in organizations: A role-system analysis'. Academy of Management Journal 26: 156-162.

Cheng, Joseph L. C.

1984 Organizational coordination, uncertainty, and peformance: An integrative study'. Human Relations 37: 829-851. 
Cheng. Joseph L. C., and William McKinley 1983 'Toward an integration of organization research and practice: A contingency study of bureaucratic control and performance in scientific settings'. Administrative Science Quarterly 28: 85-100.

Clark. Burton R.

1980 'Cross-national study of academic systems' in Sociological theory and research. H. M. Blalock, Jr. (ed.), 8398. New York: The Free Press.

Crozier. Michael

1964 The Bureaucratic phenomenon. Chicago: University of Chicago.

\section{Etzioni, Amitai}

1971 'Toward a macrosociology' in Contemporary soctological theory. F. E. Katz (ed.), 161-168. New York: Random House

Galbraith, Jay R.

1972 Organization design: An information processing view' in Organization planning. J. W. Lorsch and P. R. Lawrence (eds. ), 49-74. Homewood, Ill.: IrwinDorsey.

Galbraith, Jay R.

1977 Organization destgn. Reading. Mass.: Addison-Wesley.

Georgopoulos, Basil S

1970 'An open-system theory model for organizational research' in Organizational behaviour models. A. R. Negandhi and J. P. Schwitter (eds.). 33-70. Ohio: Kent State University.

Georgopoulos, Basil S., and Floyd C. Mann 1962 The community general hospital. New York: Macmillan.

Haire. Mason. Edwin E Ghiselli, and Lyman W. Porter

1966 Managerial thinking: An international study. New York: Wiley.

Harbison, Frederick, and Charles A. Myers 1959 Management in the industrial world: An international analysis. New York: McGraw-Hill
Heydebrand, Wolf $\mathrm{V}$., (ed.)

1973 Comparative organizations: The results of empirical research. Englewood Clifts. N.J: Prentice-Hall.

Hickson, David J., C. R. Hinings, C. J. McMillan, and J. P. Schwitter

1974 'The culture-free context of organization structure: A tri-national comparıson'. Sociology 8: 59-80.

Katz, Daniel, and Robert L. Kahn

1978 The social psychology of organizarions, second edition. New York: Wiley.

Katz, Ralph, and Michael L. Tushman

1979 Communication patterns, project performance, and task characteristics: An empirical evaluation and integration in an R\&D setting: Organizational Behavior and Human Performance 23: 139-162.

Klima, Rolf and Ludger Viehoff

1977 'The sociology of science in West Germany and Austria' in The sociology of science in Europe. R. K. Merton and J. Gaston (eds.) , 145-192. Carbondale and Edwardsville: Southern Illinois University Press.

Krauze Tadeusz. Zdislaw Kowalewski, and Adam Podgorecki

1977 'The sociology of science in Poland' in The sociology of science in Europe. R. K. Merton and J. Gaston (eds.), 193-223. Carbondale and Edwardsville: Southern Illinois University Press.

Kuc, Bolec, David J. Hickson, and Charles McMillan

1980 'Centrally planned development: A comparison of Polish factories with equivalents in Britain. Japan, and Sweden'. Organization Studies 1/3: 253-270.

Kuhn. Thomas S.

1962 The structure of scientific revolutions. Chicago: University of Chicago Press.

Lawrence, Paul R. . and Jay W. Lorsch

1967 Differentiation and integration in complex organizations'. Administravive Science Quarterly 12: $1-47$. 
Lodahl, Janice B., and Gerald Gordon

1972 'The structure of scientific fields and the functioning of university graduate departments: American Sociological Review 37: 57-72.

March. James G., and Herbert A. Simon 1958 Organizations. New York: Wiley.

Meyer, Marshall W

1978 Introduction: Recent developments in organization research and theory" in Environment and organizations. M. W. Meyer and Associates (eds.), 1-19. San Francisco: Jossey-Bass.

Miller Edwin L., and Joseph L. C. Cheng

1978 'A closer look at the decision to accept an overseas position'. Management International Review' 18: 25-34.

Mintzberg. Henry

1979 The structuring of organizations. Englewood Cliffs, N.J.: Prentice-Hall.

Nagandhi, Anant R.

1974 Cross-cultural management studies: Too many conclusions, not enough conceptualization'. Management International Review 14: 59-66.

Parsons, Talcott

1951 The social system. Glencoe, Ill.: Free Press.

Pelz. Donald C., and Frank M. Andrews

1966 Scientists in organizations. New York: Wiley.

Perrow, Charles

1967 'A framework for the comparative analysis of organizations'. American Sociological Review 32: 194-209

Price, James L

1972 Handbook of organizational measurement. Lexington, Mass.: Heath.

Pugh. Derek S.

1981 'The Aston program of research: Retrospect and prospect' in Perspectives on organization design and behavior. A. H. Van de Ven and W. F Joyce (eds.), 135-166. New York: Wiley.

\section{Roberts, Karlene $\mathrm{H}$}

1970 'On looking at an elephant: An evaluation of cross-cultural research related to organizations'. Psychological Bullefin 74: 327-350.

Schollhammer, Hans

1973 'Strategies and methodologies in international business and comparative management research'. Management International Review 13: 17-32.

Szalai, Alexander

1968 'National research planning and research statistics: The case of Hungary' in Decision making in national science policy. A. De Reuck, M. Goldsmith, and J. Knight (eds.), 202211. Boston: Little, Brown and Company.

Tannenbaum, Arnold $S$, and Rohert A. Cooke

1979 'Organizational control: A review of studies employing the control graph method in Organizations alike and unlike Lammer. C. J. and D. J. Hickson (eds.), 183-210. London: Routledge and Kegan Paul.

Tannenbaum, Arnold S., Bogdan Kavcic, Menochen Rosner, Mino Vianello, and George Wieser

1974 Hierarchy in organizations. San Francisco: Jossey-Bass

Thompson. James D.

1967 Organizations in action. New York: McGraw-Hill.

Tushman, Michael L

1978 Technical communication in $R \& D$ laboratories: The impact of project work characteristics'. Academy of Management Journal 21: 624-645. 